\title{
LIII. Latent heats of vaporization and expansion
}

\section{D.L. Hammick}

To cite this article: D.L. Hammick (1922) LIII. Latent heats of vaporization and expansion, Philosophical Magazine Series 6, 44:261, 590-594, DOI: 10.1080/14786440908565198

To link to this article: http://dx.doi.org/10.1080/14786440908565198

册 Published online: 08 Apr 2009.

Submit your article to this journal 준

Џll Article views: 1

Q View related articles $₫$ 
2 lamberts. Doubtless some function of the intensity and the angle could be devised such that, in a corresponding sense, one candle-power per square centimetre would be equal to $\pi$ lamberts, but we cannot discover a function which has the least intrinsic plausibility. Doubtless the American committee have succeeded where we have failed, but they have been unduly modest in concealing their ingenuity; they may fairly be asked to explain how they have arrived at their surprising result and why they have preferred it to the simple and obvious convention which gives the result that 1 candle-power per square centimetre equals 1 lambert.

May 27, 1922,

LIII. Latent Heats of Vaporization and Expansion. By D. L. HAMmick*.

A CCORDING to van der Waals, the pressure in a A homogeneous fluid system is $p+\frac{a}{v^{2}}$. When the system expands, work is done against the pressure. The value of this work for the expansion of $1 \mathrm{gram}$ of a liquid (volume $v_{1}$ c.c.) until its volume is $v^{2}$ c.c., the specific volume of the liquid when completely vaporized, is given by

$$
\begin{aligned}
\mathrm{A} & =\int_{v_{1}}^{v_{2}}\left(p+\frac{a}{v^{2}}\right) d v \\
& =\int_{v_{1}}^{v_{2}} p d v+\int_{v_{1}}^{v_{2}} \frac{a}{v^{2}} d v \\
& =p v_{1}-p v_{2}-\frac{a}{v_{1}}+\frac{a}{v_{2}}
\end{aligned}
$$

When $r_{2}$ is large when compared with $r_{1}$, this expression becomes

$$
\mathrm{A}=-p v_{2}-\frac{a}{v_{1}},
$$

or, putting $p v_{2}$ equal approximately to $\frac{\mathrm{R}^{\prime} \mathrm{T}}{\mathrm{M}}$,

$$
\mathrm{A}=-\frac{\mathrm{RT}}{\mathrm{M}}-\frac{a}{r_{1}} \cdot \ldots \cdot \quad \cdot \quad \cdot \quad . \quad .
$$

* Communicated by the Author. 
of Vaporization and Expansion.

From (1) we have, at constant volume,

$$
\begin{aligned}
\mathrm{T}\left(\frac{d \mathrm{~A}}{d \mathrm{~T}}\right)_{v} & =-\frac{\mathrm{RT}}{\mathrm{M}}-\frac{1}{v_{1}} \cdot \frac{d a}{d \mathrm{~T}} \cdot \mathrm{T} \\
& =-\frac{\mathrm{RT}}{\mathrm{M}}-\frac{a}{v_{1}} a \mathrm{~T} \\
(\bar{u} & \left.=\frac{1}{a} \frac{d a}{d \mathrm{~T}}\right) .
\end{aligned}
$$

Hence, substituting in the equation

$$
\begin{gathered}
\mathrm{A}-\mathrm{U}=\mathrm{T}\left(\frac{d \mathrm{~A}}{d \mathrm{~T}}\right)_{v} \\
-\mathrm{U}=-\mathrm{A}+\mathrm{T} \frac{d \mathrm{~A}}{d \mathrm{~T}}=\frac{a}{v_{1}}(1-\bar{a} \mathrm{~T}) \quad . \quad \cdot . \\
=\lambda_{\mathrm{ex} .}, \text { the latent heat of the expansion. }
\end{gathered}
$$

Now Davies (Phil. Mag. [6] xxiv. p. 421) has obtained the following expression for $\pi$, the initial pressure in a fluid:-

$$
\pi=\frac{4 \mathrm{R}}{v_{c}}\left(2 \mathrm{~T}_{c}-\mathrm{T}\right)
$$

( $v_{c}$ and $T_{c}$ are critical volume and temperature).

Hence

$$
\frac{1}{\pi}\left(\frac{d \pi}{d{ }^{\prime} \mathrm{T}}\right)_{v}=-\frac{1}{2 \overline{\mathrm{T}}_{c}-\mathrm{T}^{\prime}}
$$

Davies has also shown (Phil. Mag. [6] xxiii. p. 415) that $\frac{1}{2 \mathrm{~T}_{c}-\mathrm{T}}=\alpha$, the coefficient of cubical expansion, so that

$$
\frac{1}{\pi}\left(\frac{d \pi}{d \mathrm{~T}}\right)_{v}=-\alpha
$$

But, if $\pi=\frac{i t}{v^{2}}$, we get from (3) :

Substituting in (2)

$$
\frac{1}{a}\left(\frac{d a}{d \mathrm{~T}}\right)_{v}=-a
$$

$$
\lambda_{\mathrm{ex} .}=\frac{a}{v}(1+\alpha \mathrm{T}) \cdot \ldots . . .
$$

When $\mathrm{T}=0$, we find $\lambda_{\mathrm{ex}}=\frac{a}{v_{0}}$; in other words, at the absolute zero the expression becomes identical with Bakker's expression for the latent heat of vaporizalion. 
The question now arises as to the connexion between the value for the latent heat of expansion as given by (4) and the latent heat of vaporization at ordinary temperatures. The two latent heats would be equal, provided that no change in the internal energy of the substance occurred during the transition, at constant volume, from the liquid to the vapour phase. In other words, the condition for equality is :

$$
\int_{0}^{\mathrm{T}} \mathrm{C}_{v} d \mathrm{~T}-\int_{0}^{\mathrm{T}} c_{v} d \mathrm{~T}=0 . \quad \cdot . \cdot . \cdot
$$

$\left(\mathrm{C}_{v}, c\right.$ are the specific heats at constant rolume respectively.)

If (5) does not hold, then the difference between the latent heat of vaporization and $\lambda_{\text {ex. }}$ of equation (4) will be

$$
\int_{0}^{\mathrm{T}}\left(\mathrm{C}_{\boldsymbol{v}}-c_{v}\right) d \mathrm{~T}=\mathrm{H}
$$

Again, if during the passage from the liquid to the gaseous state a change in molecular aggregation occurs, a further quantity of heat, $h$, representing heat of association, must be taken into consideration. Hence we may put

$$
\lambda_{\text {vap. }}=\lambda_{\text {ex. }}+\mathrm{H}+h . \quad \text {. . . . } .
$$

In the Table values of $\lambda_{\text {ex. }}$, calculated according to equation (4) at the boiling-point, are compared with the observed values of $\lambda_{\text {vap. }}$, the latent heat of vaporization. Values of " $a$ " are given as atmospheres pressure $\div$ (volume of 1 gramme molecule of gas at N.T.P.) ${ }^{2}$ (Guye and Frederich, Arch. Sci. phys, et natur. Genève, ix. p. 22, 1900). Specific volumes and $\alpha$, the coefficients of expansion, are taken from Young (Sci. Proc. Roy. Dubl. Soc. xii. p. 414, 1910) and Tyrer (Trans. Chem. Soc. 1914, p. 2534). The latent heats of vaporization refer to 1 gramme of liquid, and are mainly Young's values (loc. cit.).

It will be seen from the Table that the values of $\lambda_{\text {ex, }}$ at the boiling-point agree very well with the values of the latent beat of vaporization. At the boiling-point, therefore, we have, in equation (6),

$$
\mathrm{H}+h=0 \text {. }
$$

For "normal" or unassociated liquids $h=0$, and hence

$$
\mathrm{H}=\int_{0}^{\mathrm{T}}\left(\mathrm{C}_{v}-c_{v}\right) d \mathrm{~T}=0 .
$$


of Vaporization and Expansion.

TABLE.

\begin{tabular}{|c|c|c|c|c|c|c|c|c|}
\hline Substance. & $\begin{array}{c}\mathrm{T}_{\text {b.p. }} \\
\circ \mathrm{A} .\end{array}$ & $\frac{a .}{\frac{a t s .}{(22 \cdot 4 \text { litres })^{2}}}$ & $\begin{array}{c}v . \\
\text { c.c. per } \\
\text { gram. }\end{array}$ & $\mid \begin{array}{c}a \\
\vec{v} \\
\text { cals. } \\
\text { per gram. }\end{array}$ & $\alpha$. & $1+\alpha \mathrm{T}$. & \begin{tabular}{|c|}
$\lambda_{\text {ex. }}$ \\
calc. \\
cals. per gr.
\end{tabular} & $\begin{array}{c}\lambda_{\text {vap. }} \\
\text { observed. } \\
\text { cals. per gr. }\end{array}$ \\
\hline Hydrogen & $20 \cdot 3$ & $.00042^{2}$ & $1.429^{1}$ & $89 \cdot 47$ & $0_{2} 1116^{1}$ & $\dot{1} \cdot 227$ & 110 & $108 \cdot 5-$ \\
\hline Nitrogen ......... & 67 & $\cdot 00276^{2}$ & $1 \cdot 230^{4}$ & $34 \cdot 82$ & $\cdot 0_{2} 569$ & $1 \cdot 438$ & $50 \cdot 04$ & 49.83 \\
\hline Oxygen ... & 85 & $.00 \div 72$ & $.857^{4}$ & $37 \cdot 75$ & $\cdot 0_{2} 426^{4}$ & $1 \cdot 362$ & $51 \cdot 4$ & 538 \\
\hline Argon ..... & 87 & .00260 & $712^{4}$ & $27 \cdot 95$ & $\cdot 0_{2}^{2} 385^{4}$ & $1 \cdot 385$ & $38 \cdot 7$ & $37 \cdot 5^{5}$ \\
\hline Ammonia ... & 238 & $\cdot 0_{2} 798^{2}$ & $1.476^{\circ}$ & $22 \% \cdot 7$ & $\cdot 0_{2} 176$ & $1 \cdot 419$ & 323 & $321^{7}$ \\
\hline $\mathrm{N}_{2} \mathrm{O} \ldots \ldots \ldots \ldots \ldots$ & 253 & .0750 & 1.00 & $47 \cdot 15$ & $\cdot 0_{2} 186$ & 1.472 & $69 \cdot 4$ & $66 \cdot 9$ \\
\hline Ether .............. & 308 & .03688 & $1 \cdot 431$ & 5608 & 0.169 & 1.52 & $85 \cdot 2$ & $84 \cdot 0$ \\
\hline$n$-pentaue & 313 & .03915 & $1 \cdot 622$ & $59 \cdot 96$ & $-0,163$ & 1.511 & $90 \cdot 6$ & $84 \cdot 3$ \\
\hline Methyl formate ... & 313 & .02355 & $1 \cdot 059$ & $75 \cdot 22$ & .02157 & 1.491 & $112 \cdot 1$ & $110 \cdot 6$ \\
\hline …......... & 323 & 02412 & $\cdot 822$ & $61 \cdot 8$ & $0_{2} 126$ & 1.407 & 86.95 & $85 \cdot 0$ \\
\hline Etbyl formate & 323 & .03302 & $1 \cdot 133$ & $64 \cdot 64$ & $\cdot 0,159$ & 1.513 & $97 \cdot 8$ & $97 \cdot 9$ \\
\hline Methyl acetate & 333 & $\cdot 03316$ & $1 \cdot 136$ & $61 \cdot 88$ & $0_{2} 158$ & 1.528 & $94 \cdot 6$ & $98 \cdot 6$ \\
\hline Ethyl acetate.. & 343 & $\cdot 04383$ & 1.20 & $57 \cdot 39$ & .02152 & 1.521 & $87 \cdot 3$ & $85 \cdot 8$ \\
\hline$n$-hexane ........ & 343 & 05383 & 1.633 & $54 \cdot 12$ & .02159 & $1 \cdot 544$ & $83 \cdot 6$ & $81 \cdot 9^{10}$ \\
\hline Fluor-benzene...... & 353 & .04272 & 1.053 & 53.61 & $\mathrm{O}_{2} 142$ & $1 \cdot 503$ & $80 \cdot 6$ & $80 \cdot 1$ \\
\hline Propyl formate ... & 353 & .04388 & $1 \cdot 199$ & $57 \cdot 46$ & $.0,150$ & $1 \cdot 530$ & $87 \cdot 9$ & $87 \cdot 5$ \\
\hline Metbyl propionate & 353 & .04330 & $1 \cdot 189$ & $57 \cdot 17$ & $.0,166$ & $1 \cdot 586$ & $90 \cdot 7$ & $89 \cdot 0^{\mathrm{B}}$ \\
\hline $\mathrm{COl}_{4}, \ldots \ldots \ldots \ldots \ldots$ & 353 & 04148 & 676 & $31 \cdot 6$ & $.02\llcorner 35$ & $1 \cdot 470$ & $46 \cdot 7$ & $46 \cdot 0$ \\
\hline Benzene & 353 & .03945 (м). & $1 \cdot 233$ & 64.08 & $\cdot 0_{2} 138$ & $1 \cdot 487$ & $95 \cdot 2$ & $95 \cdot 4$ \\
\hline$n$-heptane $\quad \ldots \ldots \ldots$ & 373 & $\cdot 06876$ & $1 \cdot 633$ & $51 \cdot 26$ & 0.156 & 1.582 & $81 \cdot 1$ & $75 \cdot 8$ \\
\hline Propyl acetate ... & 373 & $\cdot 05659$ & $1-257$ & $52 \cdot 67$ & $\cdot 0_{2} 155$ & 1.578 & $83 \cdot 1$ & $80 \cdot 5^{9}$ \\
\hline Ethyl propionate.. & 373 & $\cdot 05582$ & $1 \cdot 258$ & $51 \cdot 9$ & $\cdot 0_{2} 159$ & 1.593 & $82 \cdot 7$ & $81 \cdot 8^{8}$ \\
\hline Methyl butyrate... & 373 & $\cdot 05577$ & $1 \cdot 240$ & 5255 & .02156 & $1 \cdot 581$ & $83 \cdot 1$ & $79 \cdot 7^{8}$ \\
\hline Methyl isobutyrate & 363 & .05339 & 1.239 & $50 \%$ & $\cdot 0_{2} 155$ & $1 \cdot 565$ & $78 \cdot 7$ & $76 \cdot 3$ \\
\hline Toluene & 383 & 05240 & 1.283 & 5875 & $\cdot 0_{2} 125$ & $1 \cdot 478$ & $86 \cdot 8$ & $868^{3}$ \\
\hline $\mathrm{SnCl}_{4}, \ldots \ldots \ldots \ldots \ldots$ & 383 & $\cdot 05926$ & $\cdot 5021$ & $21 \cdot 12$ & $\cdot 0_{2} 141$ & $1 \cdot 542$ & $32 \cdot 6$ & $31 \cdot 6$ \\
\hline$n$-octane $\ldots \ldots \ldots \ldots$ & 393 & 08351 & $1 \cdot 621$ & $48 \cdot 2$ & $\cdot 0_{2} 154$ & $1 \cdot 606$ & $77 \cdot 4$ & $77 \cdot 4$ \\
\hline Chlor-benzene...... & 404 & .05580 & .983 & $47 \cdot 54$ & $\cdot 0_{2}^{2} 124$ & $1 \cdot 506$ & $71 \cdot 6$ & $74 \cdot 2$ \\
\hline Bromo-benzene ... & 433 & .05692 & 769 & $3 b \cdot 5$ & $\cdot 0_{2} 113$ & $1 \cdot 490$ & 544 & $55 \cdot 2$ \\
\hline Iodo-benzene ......... & 453 & .06592 & .633 & $30 \cdot 5$ & $\cdot 0_{2}^{2} 114$ & 1.516 & $46 \cdot 3$ & $46 \cdot \overline{7}$ \\
\hline Acetic acid... ...... & 393 & .03732 & 1.068 & $118 \cdot 2$ & $.0,123$ & $1 \cdot 484$ & $176 \cdot 0$ & $94 \cdot 4$ \\
\hline Water ................... & 373 & .0118 & $1 \cdot 044$ & $424 \cdot 7$ & .03766 & 1.286 & 546 & 539 \\
\hline Acotone & 329 & .02617 & $1 \cdot 321$ & $71 \cdot 56$ & $0_{2} 149$ & $1 \cdot 492$ & $106: 8$ & $125 \cdot 3$ \\
\hline Ethyl alcohol ....... & 353 & .02512 & $1 \cdot 360$ & $106 \cdot 3$ & $-0_{2} 125$ & $1 \cdot 441$ & 153 & $220 \cdot 9$ \\
\hline Methyl alcohol ... & 333 & .01959 & $1 \cdot 324$ & $176 \cdot 0$ & $0_{2} 121$ & $1 \cdot 402$ & $246 \cdot 6$ & $289 \cdot 2$ \\
\hline
\end{tabular}

1 Dewar.

2 Kaye and Laby's Tables.

3 Keesom and Onnes (1913).

4 Baly and Donnan, Jour, Chem. Soc. Ixxxi. p. 907 (1902).

5 Eucken, Ber. deut. phys. Geselisch. Iviii. p. 4 (1916).

6 Lunge.

$r$ Estreicher.

8 Marshal and Ramsay, Phil. Mag. (5) xli. p. 28 (1896).

9 Brown, Jour. Chem. Soc. lxxxiii. p. 987 (1903), lxxxvii. p. 265 (1905).

10 Tyrer.

Phil. Mag. Ser. 6. Vol. 44. No. 261. Sept. 1922. 2 Q 
At the end of the Table are given some results for liquids ordinarily regarded as associated. It will be noticed that in the case of water the value of $\mathrm{H}+h$ is approximately zero ; in other words, $h+\mathrm{H}$ must be nearly equal but opposite in sign.

Agreement between the values of $\lambda_{\text {ex }}$ and $\lambda_{\text {vap. }}$ is not found at temperatures other than the boiling-point. Thus for ether at $0^{\circ}\left(\mathrm{C}, \lambda_{\text {ex. }}=85.5\right.$ cals. ; $\lambda_{\text {vap. }}=92.5$ cals. And from equation (4) it is easy to show that the slope of the $\lambda_{\text {ex. }}$ curve is given by

$$
\frac{1}{\lambda_{\mathrm{ex}} .} \frac{d \lambda_{\mathrm{ex} .}}{d \mathrm{~T}}=-\frac{\alpha^{2} \mathrm{~T}}{1+d \mathrm{~T}}
$$

Now at the boiling-point, $\alpha \mathrm{T}$ is approximately $\cdot 5$ (vide Table above. Hence

$$
\frac{1}{\lambda_{\text {ex. }}} \frac{d \lambda_{\text {ex. }}}{d^{\prime} L^{\prime}}=-33 \alpha .
$$

The average value of $\frac{1}{\lambda_{v}} \cdot \frac{d \lambda_{\text {rap. }}}{d \mathrm{~T}}$ in the neighbourhood of the boiling-point is $2 \alpha-3 \alpha$.

The Dyson Perrins Laboratory, Oxford. May 12th, 1922.

LIV. On the Faraday-Tube Theory of Electro-Magnetism. By the late WiLiIAM Gordon Brown* .

1. THE method of describing a field of force by means of 1 lines or tubes of induction, which originated with Faraday, was given a quantitative form by Sir J.J. Thomson $\dagger$, and further discussed by N. Campbell in his book 'Modern Electrical Theory.' Since Maxwell himself looked on his work as a mathematical theory of Faraday's lines of force, one is tempted to examine the original physical theory for hints

* Communicated by Dr. C. G. Knott, F.R.S., General Secretary, R.S.E. The young author had just fnished his school life at George Watson's College, Edinburgh, when the outbreak of war in 1914 called him to the service of King and Country. He met his death in France on November 13, 1916, at the age of 21 . The paper was put in final form about a year earlier when W. G. Brown, after serving in Gallipoli, was in hospital. A short sketch of his life and of his other mathematical notes will be found in the Proceedings of the Roy. Soc. Edin. val. xlii. 1921.

†' Recent Researches,' chap. i.; 'Electricity and Matter,' chap. i. 